\title{
Communities of inquiry in curriculum approach to online learning: Strengths and limitations in context
}

\author{
Trudi Cooper and Rebecca Scriven \\ Edith Cowan University
}

\begin{abstract}
The case study discussed in this article examines how the community of inquiry (CoI) model (Garrison, Anderson, \& Archer, 2010) was used to redesign the digital learning environment in the context of an Australian university. Some purposes were to replicate features of a traditional classroom and to support collaboration between professionals with different expertise. The discussion addresses three questions. Firstly, how useful was the CoI model in context and to what extent was the success (or failure) of the redevelopment attributable to the CoI? Secondly, what are the implications for current debates about the CoI model? Thirdly, what are the emergent issues and areas for future research? The paper concludes that the CoI model was useful as a communication and design heuristic rather than as a model that makes universal truth claims about the world.
\end{abstract}

\section{Introduction}

Educational models help educators to apply the findings of education research to the practical task of curriculum design, development and sequencing of educational experiences to optimise learning. In traditional classroom settings, educators and educational policymakers use multiple theories to identify processes for different aspects of the learning experience. Some models focus on the purpose and priorities in learning and teaching, as, for example, holistic development (Barnett \& Coate, 2005) or outcomes-based (Tyler, 1986). Others focus on identification of key disciplinary concepts, as in threshold concepts (Meyer, Land, \& Bailie, 2010). Still other models focus on pedagogy and the sequencing of learning experiences and the relationship between learning and assessment, for example, SOLO (Biggs \& Tang, 2007)). In a digital environment, the situation is more complex for a number of reasons. Firstly, the digital environment allows possibilities that are not present in a traditional classroom. Secondly, the digital environment lacks features that exist organically in a classroom setting that may compensate for imperfect curriculum design. Finally, the design of the digital learning environment (DLE) usually involves collaboration between professionals with very different expertise (disciplinary knowledge, pedagogical knowledge and knowledge of learning technologies) and only limited overlap in knowledge and vocabulary, which may present challenges for communication.

Some benefits of a well-designed DLE are difficult to achieve in a traditional classroom, including asynchronous engagement of learners, learner-paced study and easy incorporation of multimedia resources to enrich the learning environment. Educational technology can enrich the presentation of materials, but must be informed by sound educational design (Ally, 2008; Herrington \& Oliver, 2000; Phillips, McNaught, \& Kennedy, 2012). In terms of quality of learning design, the DLE is less forgiving than the traditional classroom, and excellent learning design is especially important (Harrell, 2008). In an online environment, unlike face-to-face or blended environment, there are limited opportunities for a teacher to compensate for poor design. Teachers are not able to directly perceive when students are bored or do not understand. Peers are not as readily available to offer learning support unless the learning design actively supports this. Consequences of poor learning design are therefore more serious in a purely online environment. Poor course design contributes to low rates of student retention and success in some online courses (Simpson, 2003). Social media has changed modes of communication in everyday life (Conrad \& Donaldson, 2012) and extended digital communication literacy, but has also raised expectations about the attractiveness and usability of DLEs.

University teachers were traditionally recruited for their knowledge of their discipline and their expertise in research, but it has been acknowledged that university teachers also need to understand how students learn (Barnett \& Coate, 2005; Barrington, 2004; Marton, Hounsell \& Entwistle, 1997). As DLEs have become more ubiquitous, divisions of labour have become necessary. Academics provided the subject expertise, and some also had formal knowledge of pedagogy. Learning developers had knowledge of the 
technical possibilities of digital learning systems, and ideally also an understanding of pedagogy. Both collaborated to develop DLEs for specific courses. This collaboration had to balance three different areas of expertise, namely subject expertise, pedagogic and curriculum expertise and technological expertise, and find a common language for communication.

Presentation of the case study in this article begins with a discussion of the theoretical and practical considerations that led to the selection of the community of inquiry (CoI) framework as the main model used to structure the DLE for units in an Australian youth work degree. Later discussion examines how the case study contributes to current theoretical debates about the nature of the CoI model and will be used to identify emergent issues for future research. Terminology used to discuss course structures is not standardised. In this article the terms are used in the following way: 'course' refers to the whole program of study within the bachelor's degree award and 'unit' refers to a module within the course. 'Sessional staff' are hourly-paid casual teaching employees who do not have security of employment. 'Contract staff' are teaching staff employed on a fixed-term contract (usually 6-12 months), which is sometimes renewed. The youth work course in this case study was staffed by one full-time permanent staff member, one part-time teaching-only contract staff member and four sessional staff whose main employment was as professional youth workers.

\section{Col model}

In 2000, Garrison, Anderson, and Archer (2010) proposed a CoI model for educational developers to assist in the organisation of online and blended educational experiences. Subsequently, Archer (2010) suggested the framework could be applied to any educational setting. The original intention was to 'provide a heuristic understanding and a methodology for studying the potential and effectiveness of computer conferencing’ (Garrison,, Anderson, et al., 2010, p. 6.)

\section{Community of Inquiry}

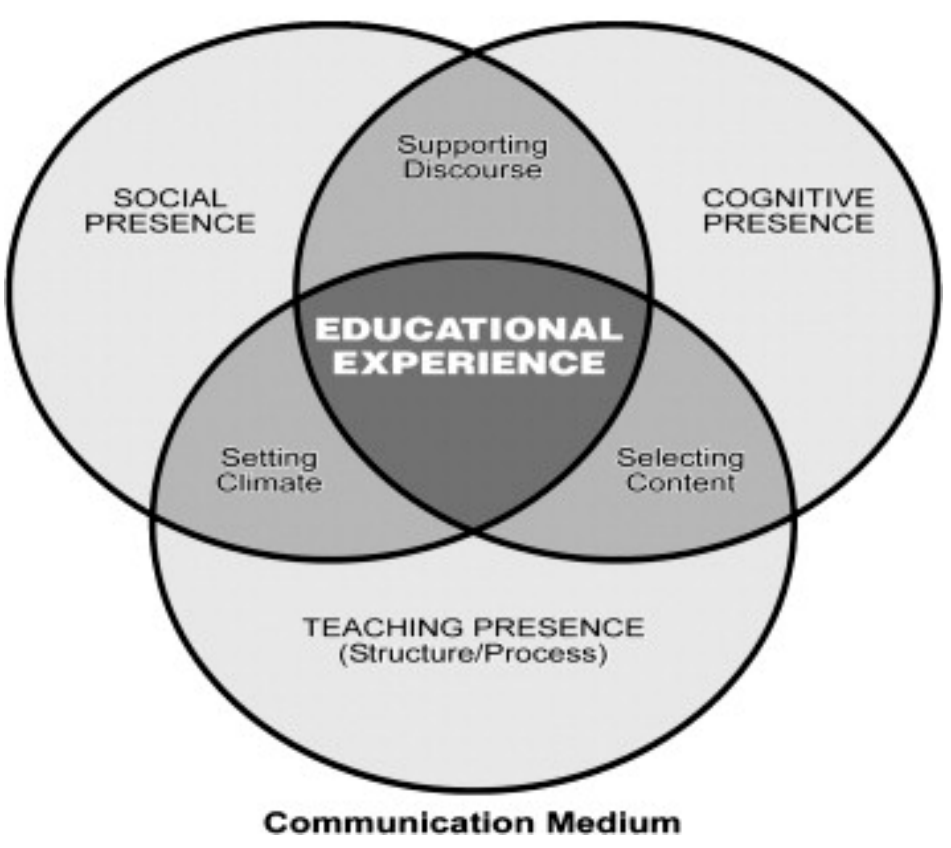

Figure 1. Elements of an educational experience (Garrison, Anderson, \& Archer, 2010)

The framework proposes that online learning is most effective if there are three elements, or presences, in the learning environment. These presences are social presence, teaching presence and cognitive presence. The three presences are viewed as overlapping. The purpose of social presence is to facilitate sufficient social connections for a CoI to function. Garrison et al. (2010) have come to understand social presence as being sequential, beginning with individual students having a sense of shared purposes with other members of the group or learning community. Later, students develop sufficient trust to enable open 
communication for the purposes of intellectual discussion. Finally, more complex interpersonal relationships might develop between students. Teaching presence also has three components described by Garrison et al. (2010) as designing the learning experiences, facilitation of the learning processes including how students interact with each other and the tasks and materials, and finally, direct teaching. In online environments, although many of the teaching presences are fulfilled by the teacher, students sometimes take on some aspects of this role, for example, directing each other to useful resources, or offering answers to other students' questions.

Cognitive presence is intended to encompass a four-phase practical inquiry model based upon Dewey's epistemology and educational theory (Garrison, 2014). The practical inquiry model is derived from Dewey's conception of the place of reflective inquiry in worthwhile educational processes. Practical inquiry includes both objective and subjective relationships to knowledge - both analysis of ideas and the construction of personal meaning. Practical inquiry also includes both thought and action. The process begins with a triggering event (problem, dilemma). Under ideal circumstances, this prompts students to exploration (identification of key features moving through to analysis), then integration (of understanding when ideas begin to fall into place and move towards synthesis), then resolution (when an acceptable solution, action or practice is found, and an integration of the student's public and private worlds is achieved). This process should not be seen as linear and is usually represented as circular. According to Garrison et al. (2010), cognitive presence, teaching presence and social presence interact to support students to move through the whole process, as far as resolution. In practice, this does not always occur (Garrison et al., 2010), but the authors interpreted this shortcoming as an implementation problem, rather than a problem with the model.

The idea that education should occur in communities of inquiry is based upon educational theories espoused by Dewey, who argued that educational experiences should be both personally meaningful and socially worthwhile, although the term community of inquiry came from Lipman (as cited in Garrison, 2014). A CoI should have a number of key features. It should provide processes to support critical inquiry, which is defined as critical thinking and problem-solving based upon a scientific method (cognitive presence). Processes are needed to support students to develop social connections and enable students to form trusting relationships and hence have open discussions that challenge the perceptions of others (social presence). Both these processes require leadership to support students through the learning process and interventions that support personal reflection to enable students to integrate their new understanding with their existing knowledge, values and worldviews (teaching presence). The framework is compatible with constructivist approaches to learning (Shea et al., 2011).

Garrison (2014) makes an important distinction between study in a CoI, where individuals interact openly with others who do not share the same beliefs and worldview, and what he calls 'ideological cocooning' (p. 148), which he argues occurs when individuals surf the Internet seeking sites that support their existing views and beliefs.

\section{Current debates}

Within the literature on CoI, much early effort was directed towards validating the model (Garrison et al., 2010), explicating the three main constructs and the relationships between them (Garrison, ClevelandInnes, \& Fung, 2010) and in validating the tools used to test implementation and outcomes of the model, for example, Akyol, Ice, Garrison, and Mitchell (2010) and Díaz, Swan, Ice, and Kupczynski (2010).

The CoI model has generated a large volume of research, the breadth of which is illustrated by these examples: an examination of how metacognition related to the different constructs (Akyol \& Garrison, 2011); the impact of course duration (Akyol, Vaughan, \& Garrison, 2009); CoI as a research method (Golding, 2015); a demonstration project in history (Stover \& Pollock, 2014); and the use of mini-lectures to strengthen teaching presence (Dringus, Snyder, \& Terrell, 2010). Vaughan (2010) developed a protocol for use by educational developers using the CoI framework in a blended learning context. The concept of community has been discussed from a number of perspectives. Akyol, Garrison, and Ozden (2009) examined the differences between online and blended learning communities. Burgess, Slate, RojasLeBouef, and LaPrairie (2010) examined the use of Second Life to develop a CoI and claimed that this was achieved in two sessions, according to CoI instrumentation test results. Arbaugh, Bangert, and Cleveland-Innes (2010) examined differences in application of CoI between disciplines and concluded 
that the model may be more applicable to applied disciplines than pure disciplines. Most of the research has used one of two methodologies: either analysis of the discourse of student posts to discussion forums or student response to structured questionnaires designed to elicit self-reporting about their interactions with learning and teaching processes. Both these methodologies have limitations. Many student posts to discussion forums were a required part of the assessment process, and the types of posts students made were likely to have been influenced by their perceptions of what was expected. Students' self-reports in response to structured questionnaires predetermine the range of acceptable student responses and has been discussed elsewhere, for example, Rourke and Kanuka (2009).

There have been conceptual challenges to most aspects of the model. These include challenges to the theoretical coherence of the model and the supposed relationship between the constructs (Jézégou, 2010; Rourke \& Kanuka, 2009). The cognitive presence construct has been challenged (Rourke \& Kanuka, 2009). The social presence construct has been questioned (Annand, 2011). The completeness of the model has also been questioned (Shea \& Bidjerano, 2012, 2013; Shea et al., 2011; Shea et al., 2014).

Rourke and Kanuka (2009) in a meta-analysis of previous empirical research raised methodological concerns about the use of self-report as the measure of student learning. Setting aside these concerns, they found very little evidence of either deep learning, or of how, in practice, the model promoted the practical inquiry processes that were central to cognitive presence. They concluded that, in practice, the CoI model did not provide an environment that promoted deep learning, and did not provide an adequate theoretical framework for research. Jézégou (2010) critiqued the concept of community of inquiry, questioning the epistemological foundations of the model and suggested that the links between the constructs were not adequately explicated. She suggested that the term 'community' should not be applied uncritically to virtual groupings and communications typical in e-learning. She argued that a central facet of community is self-direction and voluntary engagement with others, which the e-learning environment does not facilitate. Rourke and Kanuka (2009) had observed that some online courses awarded marks quantitatively for the number of posts (or deducted for lack of posts) and this distorts the idea of free participation.

Annand (2011) questioned whether social presence was necessary to promote deep meaningful learning or higher levels of cognitive processing. He argued that there was very little evidence from existing studies for the role of social presence as a precursor or enabler of cognitive presence. This finding was supported by Oyarzun and Morrison (2013), who noted that students rarely challenged each other in argumentation. They concluded, however, that social contact might be beneficial to help students overcome feelings of isolation.

There is an ongoing discussion about whether the model should be extended. Shea et al., 2014; Shea et al., 2010 have suggested that learning presence should be added to the model, to encompass research that suggests that self-regulation is a important factor in success in e-learning (Shea \& Bidjerano, 2012, 2013; Shea et al., 2014; Shea et al., 2010).

\section{Methodology and context of case study}

This section discusses methodological considerations, including strengths and limitations of our approach and then presents the context of the project and the theoretical and practical considerations that influenced how we used the CoI model to inform the curriculum re-design. We will then discuss the learning from our project and draw conclusions about the utility of the CoI model in this context, the implications for current debates about CoI, future research and other emergent issues.

\section{Methodological considerations}

We did not initially set out to evaluate the CoI model. Our primary purpose was to develop the DLE. The focus on evaluation of the utility of the CoI, and theoretical aspects of its meaning, emerged only as we began to engage actively with the model. The overarching theoretical framework for our project was an action learning process (Boshyk \& Dilworth, 2010) to evaluate what aspects needed improvement or change, as part of our normal curriculum development process. Some of the strengths and limitations of the CoI model became apparent as we used it, and our analysis and critical reflection forms the basis of this article. Because the project was initially constructed as a practical project rather than a research 
project, there are a number of limitations to our research, but also a number of strengths. A potential limitation is that we did not collect data through surveys of student learning and details of implementation were modified in subsequent iterations (in accordance with an action learning approach); our findings are therefore not directly comparable with studies that have used this methodology. We also had incomplete access to historical student learning analytics, which we may have been able to access had this study been planned as an evaluation of CoI from the beginning. This also limits direct comparison with previous studies.

A strength of this research, however, is that we analysed the epistemic nature of claims for legitimacy made about the CoI model. To do this we added a second theoretical framework drawn from Sterman (1991) and this provided the basis of the epistemic framework used in this paper. According to Sterman (1991), a good model is a simplification device to make complex relationships comprehensible. Good models usefully simplify complex relationships. A good model should retain those relationships that are most relevant to the purpose of the model and should remove all inessential features. In a discussion of computer modelling, Sterman (1991) argued that the main purpose of a model is to aid comprehension. For a model to be useful it must simplify complex relationships (Sterman, 1991). 'The map is not the territory - and a map as detailed as the territory would be of no use (as well as being hard to fold).' (p. 5). This is an important distinction because, following this line of argument, all useful models are necessarily both false and incomplete, if considered as truth claims. Instead, Sterman argues that models should always be evaluated according to utility for purpose rather than as truth claims about the world. Our purpose for using the model was to redesign a DLE, so it would fulfil a number of educational purposes, described in the next section. Our conclusions, therefore, focus on an analysis of the utility of the model for our purposes. Our findings are therefore only generalisable to other contexts, if those contexts and purposes are similar to our own. For this reason we will describe salient features of our context, so readers can decide whether it is relevant to their circumstances.

\section{Context}

The case study formed part of a larger project to renew the curriculum for youth work degrees in four Australian universities, and was also supported by internal funding from Edith Cowan University to update the DLE. Without this funding the systematic project could not have occurred and change would have been more piecemeal. This funding provided opportunities to complete both a curriculum review and a redevelopment of the DLE. The external funding provided several opportunities. It enabled us to take time to reconsider our understanding of the purposes of higher education, its processes, and what practices are effective. We also reconsidered assumptions about effectiveness of pedagogy/andragogy and implications for how we should redevelop both online and on-campus learning. The internal funding supported the redesign and implementation of the DLE, and the project's overall aim was to upskill the teaching staff and develop their capabilities for designing, maintaining and delivering quality online experiences. However, the external funding also meant that some elements of our design process were already pre-specified.

An annual practice-focused evaluation was conducted as an integral feature of the ongoing process of review. The purpose of the annual review was to determine what features of the redesign had been successful and what aspects needed to be modified. The process used an action learning approach. The team included a learning designer, the course coordinator (who did not teach the unit) and all staff who taught the unit. The group reviewed all available data and shared their perceptions about what aspects of the unit had worked as intended, using a reflective practice method. The group reviewed data from multiple sources. Student satisfaction was gauged from formal feedback from the institutional review process, combined with informal student feedback provided to staff. Staff perceptions included feedback about problems they had encountered in teaching the unit, perceptions of assignment quality and perceptions of student engagement. The review also examined how students interacted with digital materials, especially students' questions and concerns, and their feedback about the materials and technologies used in the unit. We had access to data about the numbers of posts, the numbers of students who engaged with the materials, the duration of access to the materials, student retention rates and pass rates for students enrolled in the unit.

The annual review focused on learning and action for positive change. The review process operated in the real world to find practical solutions to problems identified by staff and students. As a starting point, 
action learning acknowledges that perfect data is unachievable, and the meaning of data is always problematised. Formal student surveys do not have a high completion rate, and although they can provide some indications of satisfaction and problems, especially the qualitative comments, they need to be analysed alongside other forms of data. The purpose of the review exercise was to try to piece together incomplete and imperfect data to interpret its holistic meaning and to consider the implications of change. The discussion examined alternative possible options, as well as practical constraints within the context. This approach provided a potentially rich picture of the processes and options from multiple perspectives including perspectives of students, teaching staff and those involved in the design of learning and teaching processes. The limitations of this approach from a positivist research perspective are that the findings are not objective because they depend on judgements made by those involved in the project, and this limits the generalisability of the findings to other contexts. From subjectivist research perspectives, this limitation is unavoidable. The findings, therefore, are exploratory rather than explanatory.

\section{Institutional context of implementation}

The university had a long tradition of distance education that predated the digital era. This tradition was beneficial in some respects because it meant that distance education was accepted as an important part of the university mission. In other ways, the tradition was problematic because the transition between paperbased distance education delivery and online delivery had occurred in stages, occurring sometimes while the technologies were still underdeveloped. We have identified different phases of this transition, and the key issues within each phase are summarised in Table 1.

Table 1

Eras of e-learning

\begin{tabular}{|c|c|c|}
\hline Era & Policy trends & Practice \\
\hline $\begin{array}{l}\text { Pre-digital (until } \\
\text { the mid-1990s) }\end{array}$ & $\begin{array}{l}\text { External/extra-mural students, no attempts to } \\
\text { replicate classroom-based experience }\end{array}$ & $\begin{array}{l}\text { Paper-based materials, } \\
\text { supplemented by telephone } \\
\text { conversations and letters }\end{array}$ \\
\hline $\begin{array}{l}\text { Early digital } \\
(1995-2000)\end{array}$ & $\begin{array}{l}\text { Cost saving - digital expected to be cheaper than } \\
\text { classroom teaching; technological possibilities } \\
\text { quite limited; pressure to innovate (technology } \\
\text { driving) }\end{array}$ & $\begin{array}{l}\text { Technology drives educational } \\
\text { processes; shovelware }\end{array}$ \\
\hline $\begin{array}{l}\text { Mid-digital } \\
(2000-2010)\end{array}$ & $\begin{array}{l}\text { Proliferation of technologies, many incompletely } \\
\text { developed and not user friendly, poor } \\
\text { interoperability. Reconsiderations of new } \\
\text { educational possibility from digital environment. } \\
\text { Concern about unequal digital access (Love \& } \\
\text { Cooper, 2004) }\end{array}$ & $\begin{array}{l}\text { Tech driven vs. experimental } \\
\text { pedagogy driven vs. wait and } \\
\text { see; shovelware, plus } \\
\text { discussion forum (unfocused) }\end{array}$ \\
\hline $\begin{array}{l}\text { Maturing digital } \\
\text { (since 2010) }\end{array}$ & $\begin{array}{l}\text { Recognition that high-quality digital learning is } \\
\text { not cheaper. Focus on the educational possibilities } \\
\text { and how to make more stable, interoperable and } \\
\text { user-friendly enabling technology }\end{array}$ & $\begin{array}{l}\text { Convergence of online and } \\
\text { classroom-based learning. } \\
\text { Blended learning, flipped } \\
\text { learning and digital classroom }\end{array}$ \\
\hline
\end{tabular}

In pre-digital distance education, learning was completely separated from the classroom experience. Universities were classroom centric, on-campus learning was normalised and distance education was the 'other' - distance education was provided only for those who were unable to attend university in the 'normal' way. In the early digital era, there was little use of peer communication and distance education was still an essentially solitary pursuit. Digitally mediated communication and relationships were a novel form of communication and were not an integral part of everyday life. Most aspects of on-campus learning were not replicated in the online experience.

In a maturing digital era, there is more convergence between online and on-campus learning. In blended learning, no priority is given to either modality and attempts are made to replicate benefits of on-campus experience in online learning and vice- versa. For example, on-campus students have access to online learning resources, and online students have access to recorded lectures, and all students experience digitally mediated relationships. 


\section{Purposes of the project and use of models}

In the design of the DLE, the intention was to use models as heuristic devices to link insights from educational research with practice. The DLE was one aspect of the curriculum renewal project. The main purposes of the redesign of the DLE were to:

(1) improve engagement and authentic learning for online students (and also augment the blended learning process for on-campus students)

(2) build in activities that will help students to make the transition to university learning (this is not discussed in this article but will be discussed in a future publication from the project)

(3) provide more support for students to "think sociologically", to use academic research and to read materials and texts to interrogate their common-sense assumptions

(4) support students to integrate their academic learning with their experiences and their worldview

(5) provide learning experiences for online and on-campus students that were qualitatively similar.

Several models were used during the process of curriculum design that influenced decision-making about the DLE. These models are summarised in Table 2, to provide an overview of the context; however, they are not the main focus of the discussion in this article.

Table 2

Models relevant to different parts of the project

\begin{tabular}{ll}
\hline Model & Purpose of model \\
\hline Barnett \& Coate (Barnett \& Coate, 2005) & $\begin{array}{l}\text { Overarching purposes of youth work degree; course } \\
\text { learning outcomes; unit outcomes } \\
\text { Selection of learning experiences; key theoretical } \\
\text { Threshold concepts (Meyer et al., 2010) } \\
\begin{array}{l}\text { Concepts for each unit } \\
\text { Organisation and design of DLE } \\
\text { Deven principles for good practice in } \\
\text { undergraduate education (Chickering \& Gamson, }\end{array}\end{array}$ \\
$\begin{array}{l}\text { 1987) } \\
\text { SOLO/constructive alignment (Biggs \& Tang, learning tasks and DLE } \\
\text { 2007) }\end{array}$ & $\begin{array}{l}\text { Structuring assessment to strengthen learning } \\
\text { Action learning (Boshyk \& Dilworth, 2010) }\end{array}$ \\
$\begin{array}{l}\text { Action learning and planning change for future } \\
\text { Edith Cowan University Quality Assurance } \\
\text { Guidelines for Online Delivery }\end{array}$ & $\begin{array}{l}\text { Improving existing standards for online units, } \\
\text { online delivery, structure and navigation of online } \\
\text { content. }\end{array}$ \\
\hline
\end{tabular}

\section{Tale of 'Youth Issues'}

For our case study we focused on the development of one unit to illustrate how the CoI model was used to develop the DLE. The case study unit explored youth issues from a sociological perspective. The unit was a first-year unit, offered to students from various degrees and was available as an elective. Learning designers were involved throughout the redevelopment, as recommended by Caplan and Graham (2008, p. 245). The learning designer provided staff training and support for technological solutions on a just-intime individual basis.

The unit was first offered in the pre-digital era, as an advanced-level final-year unit. Off-campus students were provided with written study materials and received a printed book of prescribed readings. Review questions allowed self-testing of learning. Assessment for on-campus students was through a small group project. Off-campus students worked alone to produce a report.

During the late 1990s, in the early digital era, the unit was digitised as shovelware, without significant changes to the materials or activities. In the mid-digital era, the unit became an introductory first-year unit. Content was updated and modified to reflect the changed level of the unit, but the format of the unit was essentially unchanged. Later, as technology changed, discussion boards were introduced, but were 
used as bulletin boards rather than for focused threaded discussion. By 2011, as the digital era was maturing, this project commenced to redesign the DLE.

\section{Areas identified for improvement}

Before redevelopment, the course was taught on-campus through a two-hour lecture plus a one-hour tutorial, and online through written course materials, an unstructured electronic discussion forum and tutor support by email. As part of the curriculum renewal process, staff identified several areas for improvement in this course, even though previous student evaluations were positive. The main areas of intended improvement were to:

- improve support for transition to university

- $\quad$ incorporate more active learning and peer support

- $\quad$ make the online and on-campus experiences more similar.

\section{Anticipated benefits}

The anticipated benefits from the use of the CoI as a framework for the DLE was that it would enhance learning opportunities for online students to:

- form learning communities

- $\quad$ engage in meaningful discussion

- $\quad$ become more active in their learning.

We used the same DLE for all students, to promote convergence between online and on-campus delivery, but used separate discussion forums for online and on-campus students to cater for their different needs. The renewed site used multiple modes of interaction including peer-to-peer interaction and teacher-peer interaction. Multimodal teacher-student interaction was used to extend discussion, to provide encouragement, to provide feedback and to support peer discussion (teaching presence). The DLE for online students contained a social area for students to introduce themselves, make social connections with each other and to hold social conversations throughout the unit. This was intended to reduce isolation and build sufficient trust to allow open discussions, in the weekly threads (social presence). There were structured weekly discussion threads related to the topic or one of the activities. These were intended to strengthen cognitive presence. In the materials, the concept of learning communities was explicitly discussed, and examples were provided to illustrate how peer learning might work, the benefits that might accrue, and invitations to participate (teaching presence). Teaching presence was expected to be mostly reliant on the interventions of the tutor (by weekly recordings, on the discussion forum, by email to the whole group and to individuals), but also offered opportunities to students to supports each other's learning. Participation in the discussion forum was not an assessment requirement. We decided interactions on the discussion forum should be completely voluntary. However, because we wanted convergence between the online and on-campus modes, online students were required to use an online collaboration tool for communications as part of their assessment. This enabled the tutor to monitor communications between pairs, and was useful where there were difficulties, and provided clear evidence if one member of the team did not contribute.

The DLE provided a repository for all course materials and PowerPoint presentations. This meant that staff were not under pressure to present all materials and could focus on student support. The DLE contained a list of approved websites and journals. This was intended to help students locate websites where they would find high-quality relevant research and provide an alternative to 'just Google'. The DLE provided information and resources to support transition to university, including academic support, materials to support group learning, collaboration without plagiarism, expectations of independent university learning and links to tip sheets on a variety of academic skills. Students could find links to library resources, advice on library services and contact details for academic advisors and English language support. Another section of the site provided a space for students to share resources they generated.

To build learning communities, we developed a group project that had differentiated roles as part of the assessment for on-campus students. In the structured tasks, group members collaborated on a joint project 
but had different roles and tasks that were assessed individually. This task was intended to actively support students to learn how to collaborate in academic tasks and develop their teamwork skills. The learning materials provided group collaboration tools and advice about how to negotiate tasks, resolve conflict and ensure equitable workload. We hoped to extend this approach to online students but decided that it would be best to test the idea on campus, where adjustments and support could be offered more easily. For online students, we developed a supported virtual partnered project, which combined both collaboration and individual work. A wiki was used for research collaboration in the partnered project and for communication with their partner. Structured discussion forums were used to discuss activities and topics, similar to on-campus class discussions and to support cognitive presence (Garrison, (2010). Allocated online discussion groups were used to support social presence (Garrison, 2010).

\section{Overview of implementation}

In 2013, 57 students completed the course on campus and 45 students completed online. The course materials were completely revised to reflect curriculum changes. Two staff members (one contract and one sessional) taught this unit. The sessional staff member taught on campus and online. The course was organised as two 3-hour seminars on campus and for part of each session, the two staff members teamtaught. On-campus students completed a group project, online students worked in pairs, and assessment in both cases included individual and joint components.

In 2014, 82 students completed the course on campus and 63 students completed online. The unit was taught by one contract staff member plus three sessional staff members. Additional staff were needed because of rising student numbers. The course was organised as three 3-hour seminars on campus without team teaching, which became logistically too difficult because of timetabling. The peer learning tasks were organised as before, although some changes were made to the assessment rubric and marking key.

In 2015, 84 students completed the course on campus and 50 students completed online. The course was organised as three 3-hour seminars on campus, taught separately. A partnered project was used for both online and on-campus students, and the assessment had both individual and joint components. Changes were also made to the assessment rubric and marking key.

\section{Overview of changes}

The redeveloped curriculum and DLE brought about considerable change to the unit content and delivery. The changes are summarised in Table 3.

Table 3

Changes to unit

\begin{tabular}{ll}
\hline Before & After \\
\hline Focus on information about different youth issues & Focus on learning how to learn about youth issues \\
Transmissive pedagogy, passive learner & Collaborative learning was integral \\
Assessment: knowledge of information about youth & Assessment: team collaboration plus content \\
issues & knowledge \\
Learning support not integrated & Learning support integrated \\
Teacher-led; individual learning; some group tasks & Teacher-structured and supported; individual \\
on campus but no collaboration online & learning; supported peer learning \\
Some opportunities for group work, but skills not & Group work skills explicitly taught, problems \\
explicitly taught & anticipated, staff support problem resolution \\
Some focus on integration of learning with & Strong focus on integration of learning with \\
worldview & worldview \\
\hline
\end{tabular}

\section{Action learning review}

The first annual review found that individualised staff training and support for technology was crucial to the success of the unit redevelopment and especially to the development of the DLE. Most online students commented positively on the opportunities for social connection with other students. The group assessment had a mixed response. Some on-campus students had enjoyed the project, whereas others would have preferred an individual assessment. Staff felt that the changes to the unit had strengthened the 
conceptual focus of the unit and the elements that supported transition to university had been beneficial. Student learning had become more interactive, and most students had reported they enjoyed the discussion activities. Only some students understood the difference in learning paradigm - one student complained in feedback that the lecturer was of no help; they had to learn it all themselves or from other students. The convergence between on-campus and online student experiences was greater than previously but less than originally planned. Group processes caused problems in some groups, and despite support offered by staff, assessed group projects that were unpopular with some students. In response to the feedback and discussion we modified some aspects of the group project to clarify instructions and expectations through changes to the marking rubric.

When students were asked to reflect on what they had learnt in the unit, their identified learning broadly aligned with the intended outcomes of the unit (we accept the limitations of this feedback, and only consider it in conjunction with the other data sources). Most students welcomed transition support and valued activities that connected learning with their own experience. Some online students reported frustration that their partners were not as responsive as they would have hoped, but did not blame the staff for this. Online students reported that they felt they had been well supported by the tutor.

In 2014, again several on-campus students reported they did not enjoy assessed group tasks. Although staff actively supported groups who were having difficulty, after two iterations, we concluded that this was too soon to implement this approach. For 2015, we decided to use the online paired assessment on campus. The feedback from students indicated they preferred this. The staff evaluation indicated that staff felt that the redevelopment had improved the course and achieved intended outcomes. In 2015, the feedback for the online tutor was extremely positive and exceeded the average rating for on-campus study. This is unusual.

Originally, we had intended to work towards a flipped curriculum for on-campus students, and to establish stronger learning connections between on-campus and online students, including mixed group work between on-campus and online students. These plans have been suspended because of the resistance of students to group assessments in this unit. Now both on-campus and online students complete a partnered project, and there is a greater similarity between the on-campus and online modes.

\section{Discussion}

The discussion aims to address three questions. Firstly, how useful was the CoI model in context and to what extent was the success (or failure) of the redevelopment attributable to the CoI? Secondly, what are the implications for current debates about the CoI model? Thirdly, what are the emergent issues and areas for future research?

\section{Utility of Col in context}

The CoI model was used as an organising principle alongside other models. The main purpose of the CoI was to expand opportunities for active and collaborative learning through online learning communities. The redeveloped DLE improved social presence especially for online students (more students posted items to the discussion board and participated in discussions - even though this was not mandated or assessed. Online students also used a collaborative wiki as part of the assessment. We attributed these changes to changes in the DLE guided by the use of the CoI model. The CoI model was also useful because it emphasised the need for active teaching online rather than passive response and was instrumental in ensuring that multiple modes of communication were available to online students, including peer-to-peer communications, teacher-student communications, student-teacher communication, through different media. The online student tutor actively facilitated discussions and kept students engaged in their learning. This contributed immensely to the success of the online student engagement.

The data presented in Table 4 and Figure 1 below shows the number of postings to the online student discussion forums during the three years in which the unit ran. Some of the data is incomplete due to discussion board rollover problems in 2014, and our access to Blackboard Analytics data for only two of the three years (2014-2015), but the trend is typical of student activity during semester with a peak at the 
start of semester and gradually declining as the semester continues. The 2016 data has been included in Table 4 to show a continuing increase in the number of accesses to the discussion board.

Table 4

Off-campus student discussion board participation

\begin{tabular}{lllll}
\hline Year & $\begin{array}{l}\text { Number of } \\
\text { students }\end{array}$ & $\begin{array}{l}\text { Total accesses to } \\
\text { discussion }\end{array}$ & $\begin{array}{l}\text { Accesses per } \\
\text { student }\end{array}$ & $\begin{array}{l}\text { Average time per } \\
\text { access (min.) }\end{array}$ \\
\hline 2013 & 45 & Data not available & & \\
2014 & 63 & 1561 & 18.15 & 0.55 \\
2015 & 50 & 812 & 16.24 & 0.4 \\
2016 & 51 & 1372 & 26.90 & 1.07 \\
\hline
\end{tabular}

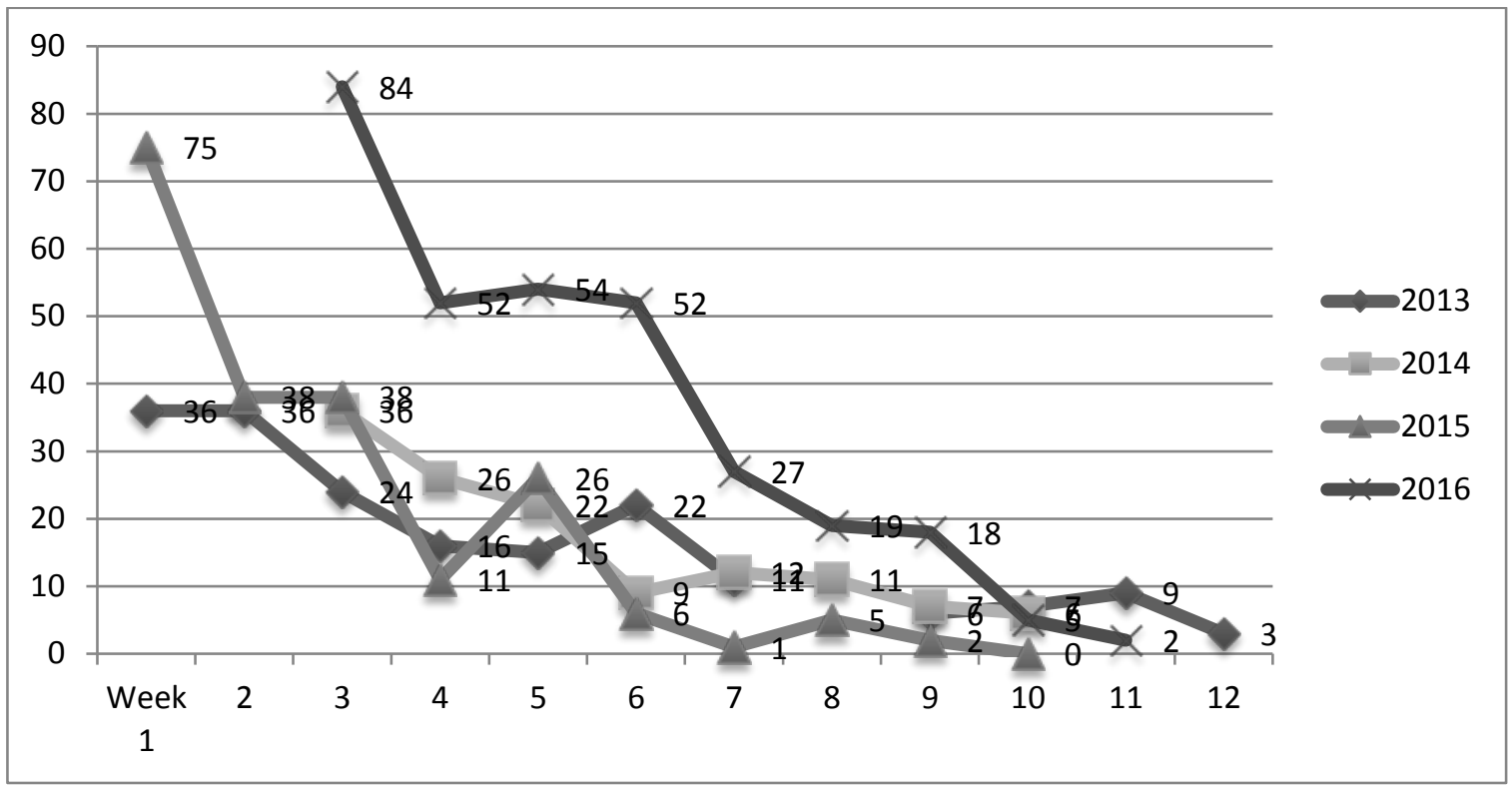

Figure 1. Number of discussion posts per week

The data is consistent with the judgement of staff that the revised unit had better supported online student engagement. For a number of reasons, we could not assess contribution of the CoI model to cognitive presence. We had no reliable baseline data because the curriculum design had been changed. From an epistemological perspective, the content and materials developed using threshold concepts, and Barnett and Coate's (2005) emphasis on "being”, were coincidentally compatible with the practical inquiry approach within cognitive presence. Youth work is an informal education practice that uses similar processes to practical inquiry, and this is reflected in teaching methods used in youth work education. The connections between the use of informal education in youth work and Dewey's educational theory have been discussed by Ord (2009), who argues that the process is closer epistemologically to Dewey than to Kolb. Notwithstanding these happy synergies, we did not formally use the practical inquiry process in our planning of the DLE. As others have commented, the practical inquiry process, which Dewey envisaged as occurring in as public dialogue in a face-to-face CoI (Klein (2013), does not translate easily to the asynchronous online environment. So, even though our design process was similar, any changes in cognitive presence cannot be attributed to the use of CoI.

The main undisputed benefit of the model was that it provided a visual summary of the features of the DLE we were trying to develop. This was especially important to communication between the learning designer who provided the technical expertise, the academic who provided the learning materials and the staff involved in the delivery of the unit. Implementation of the CoI model required intensive support for academic staff from the academic development unit, only available because we received special funding. This was crucial to the success of the implementation, both for technical support to customise the DLE and for individualised staff support to enable fuller use of the DLE. This aligns with the findings of Gregory and Salmon (2013). Intensive support would have been necessary for any improvement of the 
DLE, and therefore, this should be viewed as a necessary prerequisite to any development of the DLE rather than a limitation of the CoI model.

\section{Implications for current debates on Col}

In current debates about the CoI model, three strands dominate. First: questions about theoretical adequacy of the model and the relationships between its constituent components. Second: questions about whether the CoI model should be extended to include learning presence. Third: whether CoI provides a suitable framework for educational research.

The theoretical adequacy of the CoI model can be answered by reference to Sterman's (1991) requirements of a good model, that assessment should be made based upon utility for purpose rather than seeing models as making truth claims. In this context, the purpose was to design a DLE that would support the convergence of the learning experience of on-campus and on-line students. Our conclusions are that the CoI model was helpful for its intended purpose. We simplified the CoI model (we did not use the practical inquiry process) and we found it helped us organise our thinking about how different components of the learning experience could be best replicated in an online environment.

Learning presence is concerned with the qualities that each student brings to the process. From our perspective and for our use of the model, learning presence would not have been a useful addition to the CoI model. From an educational design perspective, some elements can be directly influenced through the design and implementation of a DLE. A learning designer can design the DLE to directly influence teaching presence, social presence and cognitive presence; however, there was little the DLE could do to directly influence learner presence. Therefore, for our purposes, learning presence complicates the model without adding to the utility. For other purposes, however, for example, when interpreting student feedback on teaching and learning processes, it could be a useful addition.

Thirdly, the answer to the question of whether CoI can provide a framework for a research agenda would depend upon the purpose of the research. Education is a multidisciplinary field, drawing on many fields including psychology, sociology, philosophy, policy, management and organisational development. No single model and no single discipline can provide a generically suitable framework for all research in education. Although the CoI model claims to integrate the social and the psychological, the tacit assumptions are those of social psychology, rather than sociology. If the proposed research is wholly contained within the discipline of social psychology, the CoI model may provide a useful framework; otherwise, it is likely to be inadequate.

\section{Emergent issues and future research}

Differences in students' circumstances have to be considered when designing a DLE to ensure that all students will find it useable. From the perspective of learning design, it might be useful to add an element that acknowledges the heterogeneity of students' circumstances. Staff observed diversity of social circumstances that lead students to enrol in online study and diversity of needs and expectations from a DLE. Understanding diversity of circumstances and expectations can help learning designers optimise the DLE to best suit the circumstances of the students they are likely to recruit. We present this discussion tentatively because our focus on action learning means that these observations would need further investigation to see whether they are found in other contexts.

Staff teaching the unit informally identified four groups of students who responded differently to the changes made. These were the 'involuntary online students'; 'social anxious'; 'efficient high achievers' and 'prisoners'.

Involuntary online students studied online because their circumstances meant they could not attend classes. On-campus study would have been their first preference. Reasons for online study included living too far from campus, work or family responsibilities precluded on-campus study, or health issues that meant they could not attend. Students whose preference would have been to study on campus were the ones who most welcomed the online collaboration and the opportunities for social interaction.

By contrast, socially anxious online students studied online because they found social contact stressful. The partnered project was not welcomed by this group, and several gained disability exemptions to enable 
them to submit a solo project instead. For this group, social presence was something they avoided, but not necessarily because they did not want anyone to challenge their beliefs.

Efficient high-achievers studied online because it was an efficient way to learn and gain good marks. They could study at times of day that suited them, the materials are readily available, and they did not need to travel. They were not socially anxious, but were not seeking a social life through their studies. They became frustrated by the time wasted in on-campus study and the lack of application of some of their peers and strongly disliked group projects because their high standards meant they did most of the work. From preference, they chose to study alone, and for them social presence is viewed as a disadvantage because it takes time, rather than because of the fear of intellectual challenge. Students in this group contributed to cognitive presence, if there was genuine intellectual discussion. Efficient highachiever students appreciated having a well-organised DLE because they could find the materials they needed easily.

Finally, prisoners study online involuntarily, but their circumstances mean they have additional constraints. Research shows that education has many benefits for prisoners (Giles, Larsen, \& Whale, 2015; Giles \& Whale, 2013). In Australia, prisoners are unable to use the Internet or any interactive features of the online experience. Since online learning has become more interactive, this group has become even more disadvantaged compared with both on-campus and online peers. In addition, there is no extra support available for teaching staff to customise materials for non-interactive, non-Internet use. A collaborative DLE design may unwittingly further disadvantage this group of students.

The most significant implication of these observations are that whilst some students actively welcomed increased social interaction in online learning, other students were unable to participate or did not welcome online social interactions. When the CoI model is used to inform the design of a DLE, this issue is not acknowledged because cognitive presence is developed through social presence, and these groups of students will be disadvantaged, excluded or forced into social interaction they do not value.

The final issue to mention is time. We found that change to curriculum and development of an interactive DLE was very time-consuming, and additional time was also required for modifications after development. The process was dependent on flexible collaboration between academic staff and learning development staff and the conscientious use of an action learning approach (see also Gregory \& Salmon, 2013). Even with additional resources, all staff put in more time than was allocated. The issue of time is one that universities often underestimate to their ultimate detriment.

\section{Conclusions}

We conclude that the CoI model provided an heuristic to develop a more lively and engaged DLE. The main use for the CoI model was to provide a visual reminder of the elements we needed to think about in the design and implementation of the DLE. We could probably have managed without the model, and may have achieved something similar, but the CoI model simplified communication about the process. For our purposes, there were practical benefits in the simplicity of the present CoI model. These would be lost if the model were further complicated, by the addition of extra elements such as learning presence. There is no reason why the CoI model should not be combined with other models when, for a particular purpose, these extra elements are required.

The process encouraged all involved to think deeply about what they were trying to do. The experience of redeveloping the DLE has led us to examine more carefully our original purpose, which was to promote active collaborative learning in the online environment. The experience has made us aware that not all students are able, or want, to participate in a social component of online learning. Although we accept that collaborative learning can promote cognitive presence, we do not believe this is the only way, and this leads us to question the necessity of the practical inquiry process within the model. It is possible practical inquiry may provide one means (although we did not use this process in our design), but we consider that for equity reasons students should be offered alternative means to develop cognitive presence, including means that do not have a social component. The revised curriculum changed what staff taught, how students worked with students, how the staff evaluated their work and how they responded to evaluation. This latter point is significant because sessional staff whose position is very tenuous often become very despondent about student feedback, especially when the feedback seems 
unfair and unbalanced, and they perceived they had no right of reply. Further research would be beneficial on a number of topics, including the use of students' self-managed CoIs (often these take the form of student initiated Facebook pages that do not include the teacher) and their relationship to official DLEs and CoIs.

\section{References}

Akyol, Z., Garrison, D. R., \& Ozden, M. Y. (2009). Online and blended communities of inquiry: Exploring the developmental and perceptional differences. International Review of Research in Open and Distance Learning, 10(6), 65-83. doi:10.19173/irrodl.v10i6.765

Akyol, Z., Ice, P., Garrison, R., \& Mitchell, R. (2010). The relationship between course socioepistemological orientations and student perceptions of community of inquiry. The Internet and Higher Education, 13(1-2), 66-68. doi:10.1016/j.iheduc.2009.12.002

Akyol, Z., Vaughan, N., \& Garrison, D. R. (2009). The impact of course duration on the development of a community of inquiry. Interactive Learning Environments, 19(3), 231-246. doi:10.1080/10494820902809147

Ally, M. (2008). Foundations of educational theory for online learning. In T. Anderson (Ed.), The theory and practice of online learning (2nd ed.) (pp. 4-31). Edmonton: Athabasca University Press.

Annand, D. (2011). Social presence within the community of inquiry framework. International Review of Research in Open and Distance Learning, 12(5), 40-56. Retrieved from http://www.irrodl.org/index.php/irrodl/article/view/924/1855

Arbaugh, J. B., Bangert, A., \& Cleveland-Innes, M. (2010). Subject matter effects and the Community of Inquiry (CoI) framework: An exploratory study. The Internet and Higher Education, 13(1-2), 37-44. doi:10.1016/j.iheduc.2009.10.006

Archer, W. (2010). Beyond online discussions: Extending the community of inquiry framework to entire courses. The Internet and Higher Education, 13(1-2), 69. doi:10.1016/j.iheduc.2009.10.005

Barnett, R., \& Coate, K. (2005). Engaging the curriculum in higher education. Maidenhead: Open University Press \& McGraw Hill Education.

Barrington, E. (2004). Teaching to student diversity in higher education: How multiple intelligence theory can help. Teaching in Higher Education, 9(4), 421-434. doi:10.1080/1356251042000252363

Biggs, J. B., \& Tang, C. (2007). Teaching for quality learning at university (3rd ed.). London: Society for Research into Higher Education.

Boshyk, Y., \& Dilworth, R. (Eds.). (2010). Action learning: History and evolution. Basingstoke: Palgrave Macmillan. doi:10.1057/9780230250734

Burgess, M. L., Slate, J. R., Rojas-LeBouef, A., \& LaPrairie, K. 2010). Teaching and learning in Second Life: Using the community of inquiry (CoI) model to support online instruction with graduate students in instructional technology. The Internet and Higher Education, 13(1-2), 84-88. doi:10.1016/j.iheduc.2009.12.003

Caplan, D., \& Graham, R. (2008). The development of online courses. In T. Anderson (Ed.), The theory and practice of online learning (2nd ed.) (pp. 245-263). Edmonton: Athabasca University Press.

Chickering, A. W., \& Gamson, Z. F. (1987). Seven principles for good practice in undergraduate education. American Association for Higher Education Bulletin, 3, 2-6. Retrieved from ERIC database. (ED282491)

Conrad, R.-M., \& Donaldson, J. A. (2012). Continuing to engage the online learner. San Fransico, CA: Jossey-Bass.

Díaz, S. R., Swan, K., Ice, P., \& Kupczynski, L. (2010). Student ratings of the importance of survey items, multiplicative factor analysis, and the validity of the community of inquiry survey. The Internet and Higher Education, 13(1-2), 22-30. doi:10.1016/j.iheduc.2009.11.004

Dringus, L. P., Snyder, M. M., \& Terrell, S. R. (2010). Facilitating discourse and enhancing teaching presence: Using mini audio presentations in online forums. The Internet and Higher Education, 13(12), 75-77. doi:10.1016/j.iheduc.2009.11.001

Garrison, D. R. (2014). Community of inquiry. In D. Coghlan \& M. Brydon-Miller (Eds.), The SAGE encyclopedia of action research (pp. 148-151). London: Sage.

Garrison, D. R., Anderson, T., \& Archer, W. (2010). The first decade of the community of inquiry framework: A retrospective. The Internet and Higher Education, 13(1-2), 5-9. doi:10.1016/j.iheduc.2009.10.003 
Garrison, D. R., Cleveland-Innes, M., \& Fung, T. S. (2010). Exploring causal relationships among teaching, cognitive and social presence: Student perceptions of the community of inquiry framework. The Internet and Higher Education, 13(1-2), 31-36. doi:10.1016/j.iheduc.2009.10.002

Giles, M., Larsen, A.-C., \& Whale, J. (2015). Carving out employment futures for Aboriginal exprisoners in the resource sector. Australian Bulletin of Labour, 41(1), 38-57.

Giles, M., \& Whale, J. (2013). Prisoner education and training and other characteristics. Joondalup: Centre for Innovative Practice.

Golding, C. (2015). The community of inquiry: Blending philosophical and empirical research. Studies in Philosophy and Education, 34(2), 205-216. doi:10.1007/s11217-014-9420-9

Gregory, J., \& Salmon, G. (2013). Professional development for online university teaching. Distance Education, 34(3), 256-270. doi:10.1080/01587919.2013.835771

Harrell, I. L. (2008). Increasing the success of online students. Inquiry, 13(1), 36-44. Retrieved from ERIC database. (EJ833911)

Herrington, J., \& Oliver, R. (2000). An instructional design framework for authentic learning environments. Educational Technology Research and Development, 48(3), 23-48. doi:10.1007/BF02319856

Jézégou, A. (2010). Community of inquiry in e-learning: A critical analysis of the Garrison and Anderson model. Journal of Distance Education (Online), 24(3), 1-12. Retrieved from http://www.ijede.ca/index.php/jde/article/view/707/1141

Klein, A. (2013). Who is in the community of inquiry? Transactions of the Charles S. Peirce Society: A Quarterly Journal in American Philosophy, 49(3), 413-423. Retrieved from https://muse.jhu.edu/article/536362/pdf

Love, T., \& Cooper, T. (2004). Designing online information systems for portfolio-based assessment: Design criteria and heuristics. Journal of Information Technology Education, 3, 65-81. Retrieved from http://jite.org/documents/Vol3/v3p065-081-127.pdf

Marton, F., Hounsell, D., \& Entwistle, N. (1997). The experience of learning: Implications for teaching and studying in higher education (2nd ed.). Edinburgh: Scottish Academic Press.

Meyer, J., Land, R., \& Bailie, C. (2010). Threshold concepts and transformational learning. Rotterdam: Sense Publishers.

Ord, J. (2009). Experiential learning in youth work in the UK: A return to Dewey. International Journal of Lifelong Education, 28(4), 493-511. doi:10.1080/02601370903031355

Oyarzun, B. A., \& Morrison, G. R. (2013). Cooperative learning effects on achievement and community of inquiry in online education. Quarterly Review of Distance Education, 14(4), 181-194. Retrieved from http://www.infoagepub.com/quarterly-review-of-distance-education.html

Phillips, R., McNaught, C., \& Kennedy, G. (2012). Evaluating e-learning: Guiding research and practice. New York, NY: Routledge.

Rourke, L., \& Kanuka, H. (2009). Learning in communities of inquiry: A review of the literature. Journal of Distance Education (Online), 23(1), 19-48. Retrieved from http://ijede.ca/index.php/jde/article/view/474/875

Shea, P., \& Bidjerano, T. (2012). Learning presence as a moderator in the community of inquiry model. Computers \& Education, 59(2), 316-326. doi:10.1016/j.compedu.2012.01.011

Shea, P., \& Bidjerano, T. (2013). Understanding distinctions in learning in hybrid, and online environments: An empirical investigation of the community of inquiry framework. Interactive Learning Environments, 21(4), 355-316. doi:10.1080/10494820.2011.584320

Shea, P., Gozza-Cohen, M., Uzuner, S., Mehta, R., Valtcheva, A. V., Hayes, S., \& Vickers, J. (2011). The community of inquiry framework meets the SOLO taxonomy: A process-product model of online learning. Educational Media International, 48(2), 101-113. doi:10.1080/09523987.2011.576514

Shea, P., Hayes, S., Uzuner-Smith, S., Gozza-Cohen, M., Vickers, J., \& Bidjerano, T. (2014). Reconceptualizing the community of inquiry framework: An exploratory analysis. The Internet and Higher Education, 23, 9-17. doi:10.1016/j.iheduc.2014.05.002

Shea, P., Hayes, S., Vickers, J., Gozza-Cohen, M., Uzuner, S., Mehta, R., ... Rangan, P. (2010). A reexamination of the community of inquiry framework: Social network and content analysis. The Internet and Higher Education, 13(1-2), 10-21. doi:10.1016/j.iheduc.2009.11.002

Simpson, O. (2003). Student retention in online open and distance learning. London: Kogan Page. Sterman, J. D. (1991). A skeptic's guide to computer models. In G. O. Barney (Ed.), Managing the nation: The microcomputer software catalog (pp. 201-229). Boulder, CO: Westview Press. 
Stover, S., \& Pollock, S. (2014). Building a community of inquiry and analytical skills in an online history course. International Journal of Teaching and Learning in Higher Education, 26(3), 393-403. Retrieved from http://www.isetl.org/ijtlhe/pdf/IJTLHE1819.pdf

Tyler, R. W. (1986). Recollections of fifty years of work in curriculum. Journal of Thought, 21(1), 70.

Vaughan, N. D. (2010). A blended community of inquiry approach: Linking student engagement and course redesign. The Internet and Higher Education, 13(1-2), 60-65. doi:10.1016/j.iheduc.2009.10.007

Corresponding author: Trudi Cooper, t.cooper@ecu.edu.au

Australasian Journal of Educational Technology @ 2017.

Please cite as: Cooper, T., \& Scriven, R. (2017). Communities of inquiry in curriculum approach to online learning: Strengths and limitations in context. Australasian Journal of Educational Technology, 33(4), 22-37. https://doi.org/10.14742/ajet.3026 